\title{
A Test of Stereophotographic Sampling in Grasslands
}

\section{W. R. PIERCE AND L. E. EDDLEMAN}

Highlight: Color stereophotography was used to sample a grassland vegetation typ for species presence and for cover. Square foot estimate plots were used as a check Three-Pee sample selection was also tested. Species identification proved difficult is dry, weathered vegetation. Cover estimates were lower for single stemmed and linea leaved weathered plants in the stereophotographic sample than in the square foot fiel estimate. Three-Pee sampling gave similar results to complete estimates.

In 1970 the authors reported on a stereo photographic technique for recording rangeland vegetation and forest understory on film for later analysis (Pierce and Eddleman, 1970). Subsequent testing of this inventory tool under demanding conditions has been completed and is the subject of this report.

A native bunchgrass range in fair condition near Missoula, Mont., was selected to provide a diversity of growth form. The vegetation aspect was dominated by a mixture of bluebunch wheatgrass (Agropyron spicatum), one-spike oatgrass (Danthonia unispicata), cheatgrass (Bromus tectorum), Japanese brome (Bromus japonicus), and Pennsylvania cinquefoil (Potentilla pennsylvanica).

\section{Methods and Results}

Sampling was carried out in midAugust, and as a consequence, grasses and most forbs were mature and dry. Since the color stereo photographic technique relies heavily on color as a means of identification, conditions were most difficult. An area $200 \times 200 \mathrm{ft}$, located on a $10 \%$ south slope, was used for the test sampling. Forty-two photographic plots one meter square were established on a uniform spacing throughout the test unit (Fig. 1).

To provide a check on the accuracy of the photographs used for estimating certain range vegetation parameters, a second and more conventional sampling technique was applied with considerable intensity. Four hundred one-square-foot plots on a uniform spacing throughout the test arca were used to determine the percent of ground cover by estimation in the field for each species of grass, forb, and shrub detected. None of these 400 plots were located on the same ground as a photographic plot.

The one-square-meter photographic plots were recorded with two types of cameras. A Hasselblad $500 \mathrm{C}$ with a 50

The authors are professor of Forest Management and associate professor of range manage ment, School of Forestry, University of Montana, Missoula.

Manuscript received February 12, 1972. $\mathrm{mm}, 75$ degree lens was the princip: piece of equipment being tested. At th same time, some of the plots wer recorded with a Nikkon-Nikkorma camera with a $28 \mathrm{~mm}$, wide-angle len: Both cameras were suspended about $5 \mathrm{f}$ above the ground and offset $18 \mathrm{cr}$ between the two exposures. A full ring strobe light (4400 ECPS) was used wit both cameras. Kodacolor X film with a ASA rating of 80 was used in bot cameras.

The day was partly cloudy with a ligh southwest wind. During periods of sur shine the plots were shaded. The focu was set at just under $5 \mathrm{ft}$, and th exposure was at $f 16$ with a shutter spee of $1 / 60$ of a second. A commercial colo film processing laboratory processed filr and prints.

Two exposures were made with th camera placed over the center of eac plot for vertical exposures; then th camera was moved to a position over th south edge of the plot for two obliqu exposures. The focus for these latte photographs was adjusted for the plo center. The entire field operation wa completed in one day.

The finished prints of each plot wer dry mounted on light cardboard with th centers of the stereo pairs 2.4 inche apart. The vertical photographs wer mounted directly under their obliqu countcrpart.

A year later the mounted photograph were used to make quick estimates of th total ground cover in each of the twent: $400 \mathrm{~cm}^{2}$ subunits of the $1-\mathrm{m}$ plots. Afte these values were recorded, the plots wer examined in detail and the percent o ground covered by each species in eac] sub-plot listed. The results of this wor] are shown by location charts beside th corresponding values resulting from th one-square-foot plots recorded in th field the year before. The distribution o two species are shown (Fig. 2 and 3) Photographic plots resulted in a con siderably lower percent ground cover fo certain species (Fig. 3) than was esti mated on the one-square-foot plots. Th, distribution pattern of each species a shown by comparison of the twe methods was essentially the same, sc 
presence detection and identification is not a problem; however, mature weathered leaves and stems of certain grasses and forbs were difficult to detect in the photograph.

Photographs underestimated bluebunch wheatgrass, cheatgrass, Japanese brome, and ballhead sandwort. Tufted grasses and broadleaf forbs yielded much the same cover estimates from both photographic and square-foot plot techniques. On the basis of the observed limitations, photographs are not recommended as an inventory technique where percent of ground cover is important, unless the photographs can be taken while the plants are green.

\section{Three-Pee Sampling}

A second study utilizing photographic plots was conducted to determine the feasibility of using Three-Pee sample selection (probability proportional to prediction) for range vegetation sampling (Grosenbaugh, 1967). The total cover estimate made for each sub-plot of each square-meter plot was applied to a random number table built expressly for this experiment using the THRRP program of Grosenbaugh (1965). Those sub-plots that had estimated values greater than or equal to the random number selected from the table in systematic order were examined in detail to correct the average of the estimated ground cover.

The corrected percent ground cover for each square-meter plot was computed by using the following formula:

Percent ground cover $=(\Sigma \mathrm{KPI} / \mathrm{M}) \times$ $(\Sigma(\mathrm{YI} / \mathrm{KPI}) / \mathrm{N})$ where $\mathrm{KPI}=$ the estimated percent ground cover for each sub-plot and $\mathrm{M}=$ the number of sub-plots per plot. YI is the more accurately determined percent ground cover; $\mathrm{N}$ is the number of these plots selected by application of the random number table.

The percent total ground cover for each photographic plot was computed by applying this formula as well as the percent ground cover on each plot of several individual species. The accuracy of the percent ground cover obtained for species found in scattered locations was not comparable to the values obtained by using all sub-plots of photographic sample locations. Minor species in the one-meter plots will frequently be missed if all sub-plots are not used for detailed examination. It is possible with Three-Pee sampling to make an estimate of the percent ground cover of individual species in each sub-plot, instead of all species, and so obtain acceptable levels of accuracy; however, this does not save
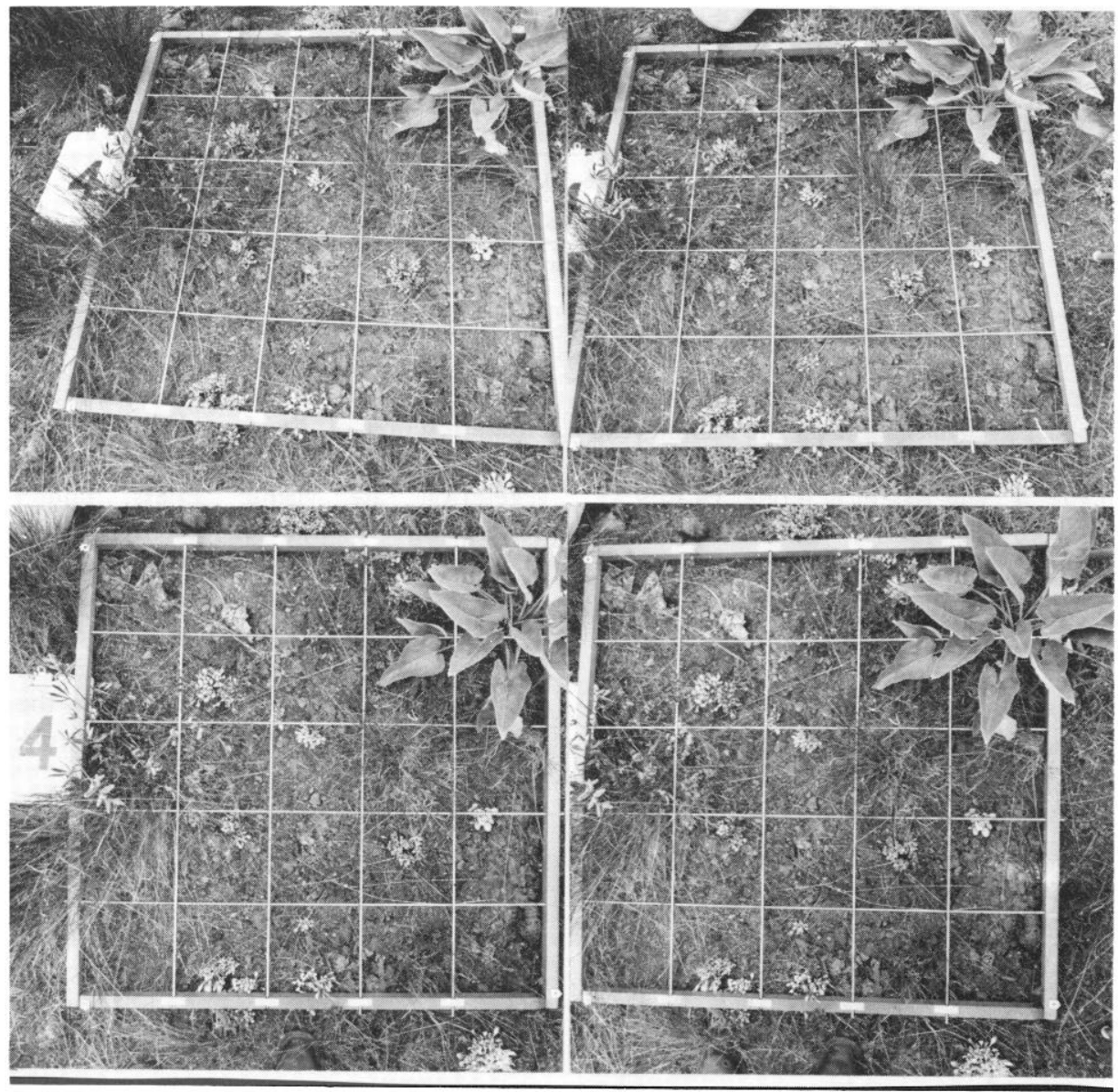

Fig. 1. A stereophotographic plot recorded when the vegetation was green /upper oblique pair and lower vertical pair).

time. The over-all averages of the ThreePee sampling as described above are shown in Table 1 along with results obtained by a detailed examination for each photographic plot. The results as tabulated for each square-meter plot are available on request from the authors. The numerical differences of percent

Photo Plots

Sq. Foot Plots

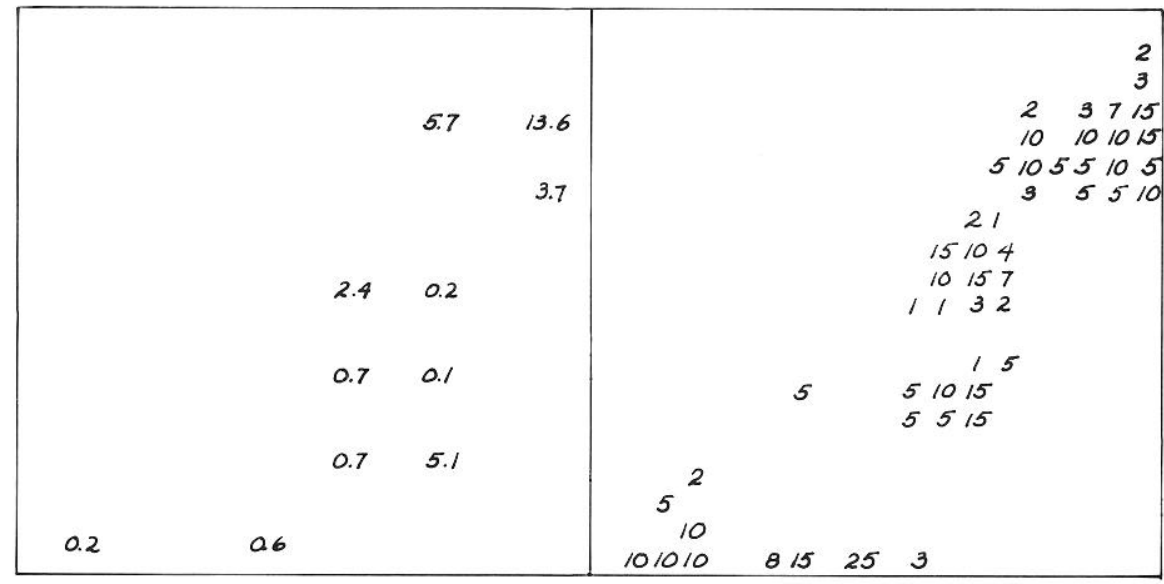

Fig. 2. Percent ground cover for Potentilla pennsylvanica. Average for all photo plots was $0.8 \%$. Average for square foot plots was $0.9 \%$.

ground cover in the square-meter plots estimated by examination of all the subplots and by the examination of only those sub-plots selected by the Three-Pee system showed no significant differences.

Essentially, the same equipment described by Pierce and Eddleman (1970) was used in this study. Since that writing, 
Table 1. A comparison of the ground cover (\%) estimates by square-meter plots using all sub-plots and using only those plots required for a Three-Pee sample.

\begin{tabular}{|c|c|c|c|c|c|c|c|c|c|c|}
\hline \multirow{2}{*}{$\begin{array}{c}\text { Cover } \\
\text { measurement }\end{array}$} & \multicolumn{2}{|c|}{ All species } & \multicolumn{2}{|l|}{ Daun ${ }^{1}$} & \multicolumn{2}{|l|}{ Pose 1} & \multicolumn{2}{|l|}{ Agsp 1 } & \multicolumn{2}{|l|}{ Pope ${ }^{1}$} \\
\hline & All S-plots & 3-P & All S-plots & $3-\mathrm{P}$ & All S-plots & 3-P & All S-plots & $3-\mathrm{P}$ & All S-plots & 3-P \\
\hline Average & 16.52 & 16.30 & 2.38 & 2.40 & 2.40 & 2.48 & 1.88 & 1.83 & 0.79 & 0.72 \\
\hline S. E. ${ }^{2}$ & & 0.182 & & 0.211 & & & & 0.244 & & \\
\hline
\end{tabular}

${ }_{2}^{1}$ Daun = Danthonia unispicata $;$ Pose = Poa secunda $;$ Agsp = Agropyron spicatum; Pope = Potentilla pennsylvanica .

however, an improved plot frame has been designed and a more convenient tripod has been found on the commercial market. The camera and tripod is shown in Fig. 4. The tripod is model Hi-Boy IV made by Quick-set, Skokie, Ill. Not shown is a black plastic shield for shading the plot.

\section{Conclusions}

The $35 \mathrm{~mm}$ photographs did not prove as functional as those recorded on $70 \mathrm{~mm}$ film by the Hasselblad; they were inferior in the following respects:

1. The resolution was not as good, and minor plants were missed freqently or could not be identified.

2. The entire one-meter plot could not be included in the field of view from five feet. This distance could be increased, but this would make adjustments of the camera awkward and the resolution would be reduced. A 60 x 80 centimeter aluminum frame has been used with the $35 \mathrm{~mm}$ camera with acceptable results.

3. The depth of field was less, which could cause difficulty in working with taller plants.

Standardized camera settings make the field work very simple and fast and result in uniform negatives which can be processed commercially. The permanent record provided by the photographs permits a highly trained technician to devote his time to this work whenever it is convenient, and questionable results can be checked at any time. The authors believe, however, that the greatest value of this technique lies in the ability to identify vegetative trends on permanently marked sampling stations. Recent work done in England by Grimes and Hybbard (1969) has recognized this value of photographic sampling. Wells (1971) has also noted the value of stereo photographs for retrieving information on species composition, cover, and herbage weight.

The effectiveness of this system of recording vegetation on stereographic photographs depends on the use of the ring-strobe light. This light around the circumference of the lens eliminates all shadows, so that both large and small vegetation are visible unless hidden behind other plants. The use of two sets of photographs, vertical and oblique, uncovers most hidden plants. If a sun shield of translucent material is used, an adjustment in exposure may be required. A camera with automatic adjustment of the exposure would cause additional prob-

\section{Photo Plots}

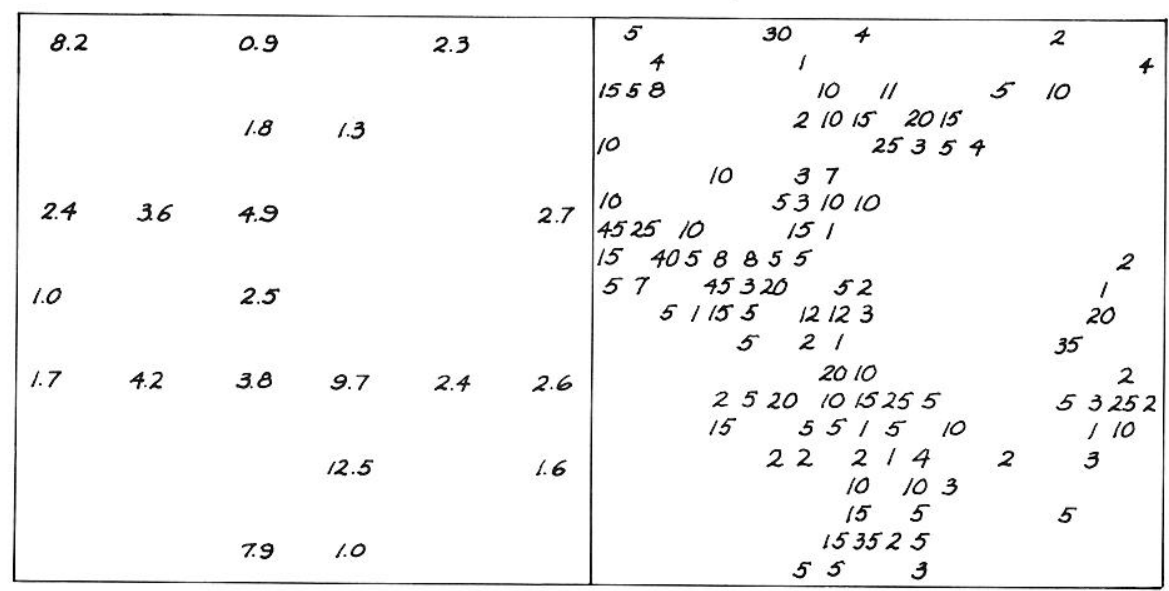

Fig. 3. Percent ground cover for Agropyron spicatum. Average for the photo plots was $1.9 \%$. Average for the square foot plots was $2.5 \%$.

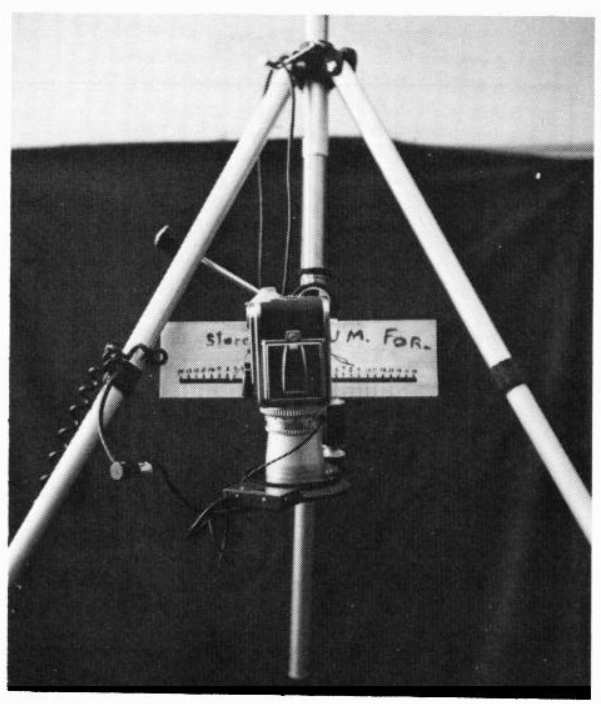

Fig. 4. Tripod and camera suspension detail. lems unless the sun shield was effective for the entire field of view. The use of two cameras providing simultaneous exposures would result in improved photographic resolution if there was any windcaused motion in the vegetation and the strobe light was not required; however, shadows are recorded when artificial light is used. Since we find shadows to be an important restriction in species identification, any technique that does not eliminate them should not be used.

Sq. Foot Plots

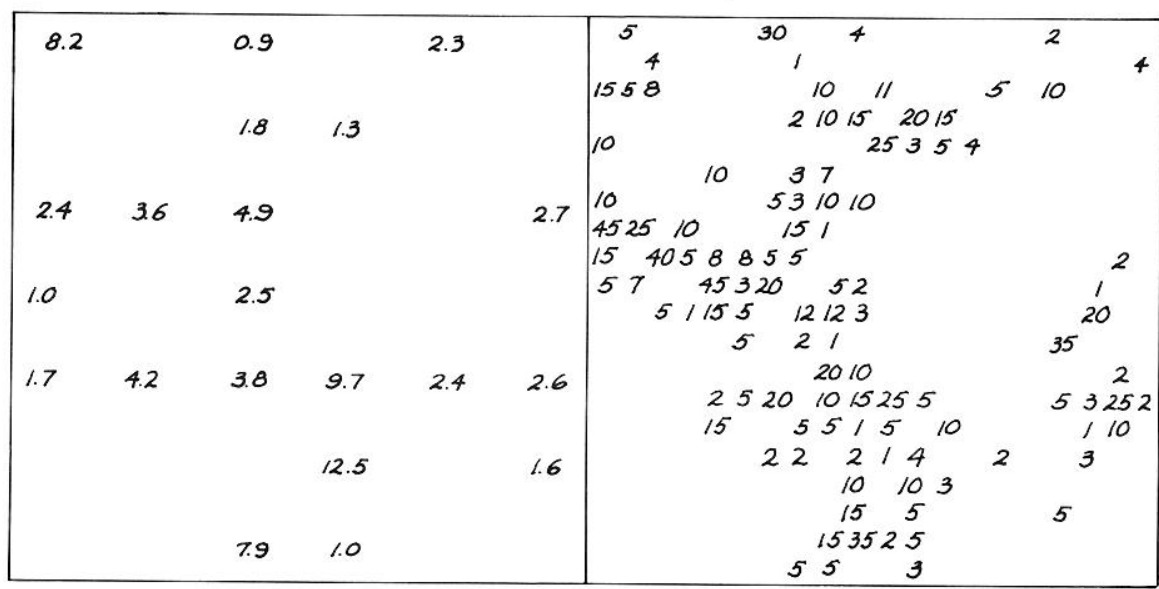

\section{Literature Cited}

Grimes, B. H., and J. C. E. Hubbard, 1969. The use of aerial photography in the nature conservance. The Photogr. J. 109 (5). 4 p. Grosenbaugh, L. R. 1965. Three-Pee sampling theory and program THRP for computer generation of selection criteria. Pacific Southwest Forest and Range Exp., Sta. Forest Serv. Res. Paper PSW21. 53 p.

Grosenbaugh, L. R. 1967. STX-Fortran-4 Program for estimates of tree populations form $3 \mathrm{P}$ sample-tree-measurement. Pacific Southwest Forest and Range Exp. Sta., Forest Serv. Res. Paper PSW13. 76 p.

Pierce, W. R., and L. E. Eddleman, 1970. A field stereo photographic technique for range vegetation analysis. J. of Range Manage. 23:218-220.

Wells, K. F. 1971. Measuring vegetation changes on fixed quadrants by vertical ground stereo photography. J. of Range Manage. 24:233-236. 